\title{
The exosomal integrin a5 $\beta 1 /$ AEP complex derived from epithelial ovarian cancer cells promotes peritoneal metastasis through regulating mesothelial cell proliferation and migration
}

\author{
Xiaoduan $\mathrm{Li}^{1} \cdot$ Meiling Tang ${ }^{1} \cdot$ Qinyi Zhu ${ }^{1} \cdot$ Xinjing Wang ${ }^{2} \cdot$ Yingying Lin $^{3} \cdot$ Xipeng Wang ${ }^{1,2}$
}

Accepted: 18 November 2019 / Published online: 21 February 2020

(C) The Author(s) 2020

\begin{abstract}
Purpose Epithelial ovarian cancer (EOC) is one of the most malignant cancers in the gynecologic system. Many patients are diagnosed at an advanced stage with disseminated intra-peritoneal metastases. EOC spreads via both direct extension and transcoelomic spread. However, the interplay between human peritoneal mesothelial cells (HPMCs) and EOC cells is still ambiguous. We hypothesize that integrins (ITG) in HPMCs may play important roles in EOC metastasis.

Methods The expression of different integrin subtypes from HPMCs was assessed using Western blotting. The expression of integrin $\alpha 5 \beta 1$ (ITGA5B1) and its co-localization with asparaginyl endopeptidase (AEP) in HPMCs derived from EOC patients (EOC-HPMCs) were assessed using immunofluorescence. The role and mechanism of the exosomal ITGA5B1/AEP complex in HPMCs was assessed using both in vitro and in vivo assays. A retrospective study involving 234 cases was carried out to assess ITGA5B1 and AEP levels in circulating sera and ascites of EOC patients, as well as associations between ITGA5B1/AEP expression and overall survival.

Results We found that ITGA5B1was highly expressed and co-localized with AEP in EOC cells, and that the exosomal ITGA5B1/AEP complex secreted by EOC cells played an important role in the proliferation and migration of HPMCs. High levels of exosomal ITGA5B1/AEP were also found in circulating sera and ascites of EOC patients, and the expression of ITGA5B1/AEP in EOC tissues was found to be negatively associated with overall survival.

Conclusions Our data indicate that EOCs may regulate the function of HPMCs through exosomal ITGA5B1/AEP, which may be crucial for peritoneal metastasis.
\end{abstract}

Keywords Epithelial ovarian cancer $\cdot$ Peritoneal metastasis $\cdot$ Integrin $\cdot$ AEP $\cdot$ HPMC

Electronic supplementary material The online version of this article (https://doi.org/10.1007/s13402-019-00486-4) contains supplementary material, which is available to authorized users.

Yingying Lin

yylin@sibs.ac.cn

$\bowtie$ Xipeng Wang

wangxipeng@xinhuamed.com.cn

1 Department of Gynecology, Shanghai First Maternity and Infant Hospital, Tongji University School of Medicine, Shanghai 201204, China

2 Department of Obstetrics and Gynecology, XinHua Hospital Affiliated to Shanghai JiaoTong University School of Medicine, Shanghai 200092, China

3 Department of Neurosurgery, RenJi Hospital, Shanghai JiaoTong University School of Medicine, Shanghai 200127, China

\section{Introduction}

Epithelial ovarian cancer (EOC) is one of the most malignant cancers occurring in the gynecologic system. In the United States alone, each year $>22,000$ new patients are diagnosed with EOC and > 14,000 patients die from it [1]. Unfortunately, it is difficult to diagnose EOC in its early stages because of a lack of comprehensive laboratory tests and specific symptoms $[2,3]$. Therefore, more than half of the EOC patients are diagnosed at advanced stages with widespread metastases. Also, due to high recurrence rates, the overall five-year survival is still low [4]. The key components of EOC progression are peritoneal dissemination, multiple organ metastases, refractory ascites and retroperitoneal lymph node involvement $[5,6]$. The diagnosis of EOC recurrence and metastasis mainly relies on detection of the biomarker carbohydrate antigen 125 (CA125) [7] combined with medical imaging clues, which 
are limited in specificity and sensitivity. Thus, new biomarkers are urgently needed for early EOC and metastasis detection.

The conventional therapy of EOC at early stages is surgical excision, while cytoreduction followed by platinum- and taxane-based chemotherapy is used for EOCs at advanced stages $[8,9]$. The mortality of EOC is directly associated with the prevalence of metastases. Approximately one-third of the EOC patients present with malignant ascites, and the presence of massive ascites is associated with a poor prognosis [10]. Trans-coelomic metastasis through the mesothelium correlates with ascites production. At advanced stages, small clusters of EOC cells in the ascites detach from the primary site and adhere to the abdominal peritoneum or omentum. When EOC cells adhere to the mesothelium of the peritoneal cavity, they proliferate, migrate and finally invade into the surrounding tissues. This indicates that EOC progression and dissemination may be regulated through cell-cell and/or cell-matrix associated adhesion mechanisms [11]. Thus, it is considered relevant to further explore contacts between EOC cells and HPMCs to unravel the mechanisms underlying peritoneal metastasis. It has been reported that inflammatory mediators and low $\mathrm{pH}$ can induce HPMCs to lose certain epithelial characteristics and to progressively acquire a fibroblast-like phenotype [12]. This epithelial to mesenchymal transition (EMT) process has also been shown to play an important role in tumorigenesis [13]. It is therefore relevant to explore the changes that take place in HPMCs and whether these changes are conducive to peritoneal EOC metastasis.

Integrins (ITGs), which are expressed on the surface of EOC cells, play important roles in the attachment of these cells to the mesothelial extracellular matrix (ECM) [14]. Integrins mediate cell-matrix and cell-cell interactions and constitute a family of transmembrane cellular receptors. They represent heterodimeric glycoproteins that consist of a larger subunit ( $\alpha$ subunit, $120-170 \mathrm{kD}$ ) and a smaller subunit ( $\beta$ subunit, 90-100 kD) [15]. Integrins can transduce signals to regulate cell growth, proliferation, differentiation and adhesion, and they are expressed on various cell types including fibroblasts, endothelial cells and immune cells [16]. Some integrins are specifically expressed on EOC cells, such as $\alpha 5 \beta 1, \alpha 2 \beta 1$ and $\alpha v \beta 3$ [16-18]. Several of them have been found to act as important mediators of EOC metastasis to the mesothelium of the peritoneal cavity. Integrin $\alpha 5$ (ITGA5) binds to integrin $\beta 1$ (ITGB1). ITGA5B1 recognizes the arginine-glycineaspartic sequence (RGD) on fibronectin, which is one of the most abundant proteins in the ECM of the EOC peritoneum and omentum [19]. As mentioned above, EOC metastasis starts with the attachment of cancer cells to mesothelial cells. This attachment can be inhibited by antibodies directed against ITGA5, ITGB1 or RGD peptides, which indicates that ITGA5B1 may play a crucial role in EOC cell binding to mesothelial cells [20]. Here, we assessed the expression of integrins from EOC-derived exosomes. Although AEP is a member of the $\mathrm{C} 13$ cysteine protease family, it generally presents as an inactive zymogen. Activation of AEP requires the removal of C-terminal and $\mathrm{N}$-terminal pro-peptidase from proAEP [21]. AEP resides in acidic lysosomes or endosomes, takes part in intracellular protein degradation and plays an important role in atherogenesis [22], immunity [23] and cancer metastasis. AEP promotes cancer metastasis via degradation of the extracellular matrix [24]. It has been reported that high AEP expression correlates with a poor prognosis and a short survival time in prostate cancer [25], colorectal cancer [26], breast cancer [24], leukemia [27] and ovarian cancer [28].

Exosomes are small extracellular vesicles ranging from 30 to $100 \mathrm{~nm}$ in size that contain functional biomolecules such as DNA, RNA, lipids and proteins. Exosomes are key mediators of cell-cell communication, and the biomolecules contained within exosomes can be transferred to recipient cells [29]. As such, they provide crosstalk between tumor cells and the tumor microenvironment (TME), which includes endothelial cells, mesothelial cells, stromal cells, fibroblasts, extracellular matrices and infiltrating immune cells, through paracrine mechanisms [30]. Brain astrocyte-derived exosomes can, for example, promote brain metastatic cancer cell outgrowth by transferring miR-19a [31]. Exosomes may also contain cell surface-anchored proteases and carriers for adhesion molecules. It has been shown that exosomes exist in the ascites of ovarian cancer patients [32]. Since advanced EOC is always accompanied by malignant ascites formation, these studies suggest that exosomes may play an important role in EOC peritoneal metastasis [33].

Since the relationship between ITGA5B1 and AEP expression in EOC has so far rarely been reported, we aimed to explore the function of the ITGA5B1/AEP complex in EOC invasion. We found that HPMC regulation through the EOC exosomal ITGA5B1/AEP complex may be a crucial step in EOC peritoneal metastasis. Furthermore, we found that the ITGA5B1/AEP complex may serve as a new biomarker and/ or therapeutic target for EOC patients.

\section{Materials and methods}

\subsection{Patients and specimens}

Epithelial ovarian cancer tissues and human omentums were collected from EOC patients and benign ovarian tumor volunteers at Shanghai First Maternity and Infant Hospital, Tongji University School of Medicine. A total of 234 surgical tissue samples were collected. None of the cancer patients received any chemotherapy before sampling. The histopathological diagnosis, stage and grade of the EOC samples were assigned according to the FIGO (International Federation of 
Gynecology and Obstetrics) classification. The objectives and implications of the results were explained clearly, and institutionally approved written informed consent was obtained from each participant. The study protocol was reviewed and approved by the Institutional Review Board of Shanghai First Maternity and Infant Hospital, in accordance with the Declaration of Helsinki.

\subsection{Enzymatic disaggregation of omentums for HPMC isolation}

Omentums (approximately $5 \mathrm{~cm}^{2}$ ) were washed and incubated in $15-20 \mathrm{ml}$ of a solution containing $0.125 \%$ trypsin and $0.01 \%$ EDTA (Trypsin-EDTA Solution, Sigma, 59428C) for $25 \mathrm{~min}$ at $37{ }^{\circ} \mathrm{C}$ with continuous rotation. Next, the suspensions were centrifuged at $1500 \mathrm{rpm}$ for $10 \mathrm{~min}$. The resulting cell pellets were washed once in low-glucose DMEM (HyClone, SH30021.01) containing $10 \%$ fetal bovine serum (FBS, Gibco, 10,099,141), resuspended in low-glucose DMEM containing 20\% FBS to a volume of $5 \mathrm{ml}$ and seeded in $25 \mathrm{~cm}^{2}$ matrix-coated tissue culture flasks. Half of the medium was exchanged $24 \mathrm{~h}$ after seeding and, thereafter, fully replaced once every third day [34].

\subsection{Cell culture and transfection}

Human EOC-derived SKOV3 cells were cultured in RPMI1640 medium (HyClone, SH30809.01B) supplemented with $10 \% \mathrm{FBS}$ and $1 \%$ antibiotics in a humidified atmosphere with $5 \% \mathrm{CO}_{2}$ at $37{ }^{\circ} \mathrm{C}$. SKOV3 cells were transfected with a luciferase reporter vector containing a puromycin resistance gene (SKOV3-luc) and grown in complete medium supplemented with $3 \mu \mathrm{g} / \mathrm{ml}$ puromycin (Shanghai MaoKang Biotechnology, MS0011-25MG). The cells were maintained in culture for no more than 10 passages and they were authenticated using short tandem repeat (STR) analysis every six months. The last test was conducted in February 2019. The cells were also authenticated by morphology, phenotype and growth characteristics, and routinely screened for mycoplasma contamination (Vazyme, MycoBlue ${ }^{\mathrm{TM}}$ Mycoplasma Detector, D101-02) at least every six months. The last test was performed in February 2019.

For stable transfection of the cells, ITGA5, ITGB1 and AEP lentiviruses were designed by Genomeditech (China) and transfections were conducted according to the manufacturer's instructions. Briefly, SKOV3 cells were seeded in 6well plates and infected with lentivirus in the presence of $6 \mu \mathrm{g} / \mathrm{ml}$ polybrene. Blasticidin $(20 \mu \mathrm{g} / \mathrm{ml})$, neomycin $(100 \mu \mathrm{g} / \mathrm{ml})$ and hygromycin $(200 \mu \mathrm{g} / \mathrm{ml})$ were used for positive cell selection.

\subsection{Characterization of HPMCs}

HPMCs were characterized by immunohistochemistry (IHC) using antibodies directed against vimentin (R\&D System, MAB21052), cytokeratin (Novus Biologicals, NB1002756), CD45 (R\&D System, MAB1430) and factor VII (KenGEN BioTECH, KGZA0084). Five random fields were analyzed at $\times 200$ magnification. HPMCs stain positive for the mesenchymal markers vimentin and cytokeratin, but negative for the macrophage marker CD45 and the endothelial marker factor VII. Hematoxylin and eosin (H\&E) stained slides were used for cell morphology assessment. HPMCs were successfully isolated from $6 \mathrm{EOC}$ patients and 6 benign ovarian tumor patients.

\subsection{Histological and immunohistochemical analysis of the ITGA5B1/AEP complex}

AEP and integrins were detected trough incubation of tissue sections overnight at $4{ }^{\circ} \mathrm{C}$ with anti-legumain (Abcam, ab125286), anti-integrin $\alpha 5$ (Abcam, ab150361) and antiintegrin $\beta 1$ (CST, 9699) antibodies. Next, the sections were incubated with HRP-conjugated anti-goat IgG (R\&D Systems, HAF017) and anti-rabbit IgG (CST, 7074) for $60 \mathrm{~min}$ at $37^{\circ} \mathrm{C}$. After rinsing three times for $5 \mathrm{~min}$ in PBS, the sections were incubated with DAB for $30 \mathrm{~s}$, counterstained with hematoxylin and dehydrated. Evaluation was performed on five fields at $\times 200$ magnification for AEP and integrin expression by two independent researchers. The AEP staining percentage (PP, percentage of positive cells) was scored as 1 , $1 \%-25 \%, 2,26 \%-50 \%, 3,51 \%-75 \%$ or $4,76 \%-100 \%$. The AEP staining intensity (SI) was scored as 0 (negative), 1 (weak), 2 (moderate) or 3 (strong). Immunoreactive scores (IRS) were obtained by combining the PP and SI scores. The IRS were divided into the following groups: $0-3$ (negative), 4-6 (weak positive), 7-9 (positive) and 10-12 (strong positive) [31].

\subsection{Immunofluorescence confocal microscopy analysis of the ITGA5B1/AEP complex}

Detection of integrin $\alpha 5$, integrin $\beta 1$ and AEP in HPMCs was performed using anti-integrin $\alpha 5$ (Abcam, ab150361), antiintegrin $\beta 1$ (Abcam, ab134179) and anti-legumain (R\&D, AF2199) antibodies. Cell nuclei were counterstained with DAPI (Sigma, D9542). Alexa Fluor 488-conjugated anti-rabbit antibody (Jackson, 111-545-003) was used for the detection of anti-integrin antibodies, and Cy3-conjugated anti-goat antibody (Jackson, 705-165-003) was used for the detection of anti-legumain antibody. Images were taken using a Zeiss LSM 510 laser confocal microscope. Quantitative analyses were performed in 5 random fields by counting the number of cells at $\times 200$ magnification. 


\subsection{Co-immunoprecipitation and Western blotting}

Cells in $10 \mathrm{~cm}$ dishes were prepared for co-IP according to the manual of the Pierce ${ }^{\mathrm{TM}}$ Co-Immunoprecipitation Kit (ThermoFisher, 26,149). After overnight incubation with anti-legumain antibody (R\&D, AF2199) the protein samples were analyzed by Western blotting (WB). Total proteins were obtained after cell lyses with RIPA and separated by $10 \%$ SDS PAGE. Next, the proteins were transferred to polyvinylidene fluoride membranes (Millipore, IPVH00010). After blocking with $5 \%$ non-fat milk for $2 \mathrm{~h}$, the membranes were incubated with primary antibodies at $4{ }^{\circ} \mathrm{C}$ overnight and subsequently incubated with a secondary HRP-conjugated antibody for $1 \mathrm{~h}$ at room temperature. The signals were visualized using a chemiluminescent HRP substrate (Millipore, WBKLS0500). FAK, phospho-FAK, Akt and Erk were evaluated as downstream members of the HPMC proliferation and migration pathway. For the assessment of epithelial-mesenchymal transition (EMT) an EMT Antibody Sampler Kit was used (CST, 9782).

\subsection{Quantitative RT-PCR}

RNA was collected using TRIzol, reverse-transcribed into cDNA and subjected to PCR using a PrimeScript RT-PCR kit (Takara, DRRo14A). The primer sequences used were as follows: Legumain forward primer 5 '-GATGAACC ACCTGCCGGATAA-3', Legumain reverse primer 5'CATCATAGTAACAGGCGTAGGACGA-3’. Integrin $\alpha 5$ forward primer 5'-AGACATTCGATCCCTCTACAACT-3' and reverse primer $5^{\prime}$-AATCGGCCAAACTCATCATGG-3'. Integrin forward primer $\beta 1$ primer $5^{\prime}-\mathrm{CAAGAGAG}$ CTGAAGACTATCCCA-3' and reverse primer $5^{\prime}$ TGAAGTCCGAAGTAATCCTCCT-3’. ZO-1 forward primer 5'-CAACATACAGTGACGCTTCACA-3' and reverse primer $5^{\circ}$-CACTATTGACGTTTCCCCACTC-3 ${ }^{\prime}$. Ecadherin forward primer 5 -CAACATACAGTGAC GCTTCACA-3' and reverse primer 5'-CACTATTG ACGTTTCCCCACTC-3 ${ }^{\circ}$. Claudin-1 forward primer 5'CCTCCTGGGAGTGATAGCAAT-3' and reverse primer 5'GGCAACTAAAATAGCCAGACCT-3`. ZEB1 forward primer $5^{\prime}$-GATGATGAATGCGAGTCAGATGC-3' and reverse primer 5'-ACAGCAGTGTCTTGTTGTTGT-3'. Ncadherin forward primer 5'-TCAGGCGTCTGTAG AGGCTT-3' and reverse primer 5'-ATGCACATCCTTCG ATAAGACTG-3 ${ }^{\circ}$. $\beta$-catenin forward primer $5{ }^{\prime}$ CCTATGCAGGGGTGGTCAAC- 3 ' and reverse primer 5'CGACCTGGAAAACGCCATCA-3`. Snail forward primer 5'-TCGGAAGCCTAACTACAGCGA-3' and reverse primer 5'-AGATGAGCATTGGCAGCGAG-3'. Slug forward primer $5^{\prime}$-CGAACTGGACACACATACAGTG-3' and reverse primer $5{ }^{`}$-CTGAGGATCTCTGGTTGTGGT-3`. GAPDH forward primer $5{ }^{`}$-GGAGCGAGATCCCTCCAAAAT-3` and reverse primer 5 '-GGCTGTTGTCATACTTCTCATGG $-3{ }^{3}$. The amplification conditions for 40 cycles consisted of denaturation at $95^{\circ} \mathrm{C}$ for $10 \mathrm{~s}$ and annealing at $60^{\circ} \mathrm{C}$ for $32 \mathrm{~s}$. The fold change was calculated as $2-\Delta \Delta \mathrm{Ct}$, where $\Delta \Delta \mathrm{Ct}=\Delta \mathrm{Ct}$ treatment $-\Delta \mathrm{Ct}$ control and $\Delta \mathrm{Ct}=\mathrm{Ct}$ target gene-Ct GAPDH.

\subsection{Exosome isolation and detection}

Sera and ascites from EOC and benign ovarian tumor patients were centrifuged for $30 \mathrm{~min}$ at $2500 \mathrm{rpm}$ to remove cell debris, followed by incubation with a Total Exosome Isolation Kit (SBI, EXOQ5A-1) overnight according to the manufacturer's instructions and centrifugation at $10000 \mathrm{xg}$ for $1 \mathrm{~h}$. To isolate exosomes from SKOV3, the cells were cultured in serum-free RPMI-1640 medium for $24 \mathrm{~h}$. Next, the supernatants were collected and centrifuged two times $(1000 \mathrm{xg}$ for $10 \mathrm{~min}$ and $3000 \mathrm{xg}$ for $30 \mathrm{~min}$ to remove cells and/or fragments, followed by the addition of Total Exosome Isolation Reagent (Life Technologies, 4,478,359) overnight and centrifugation at $10,000 \mathrm{xg}$ for $1 \mathrm{~h}$ at $4{ }^{\circ} \mathrm{C}$. The resulting exosomes were resuspended in PBS and stored at $-80{ }^{\circ} \mathrm{C}$. The concentration of exosomes was determined using a BCA Protein Assay.

To detect exosomes derived from SKOV3 cells acting on HPMCs, they were labeled with SYTO ${ }^{\circledR}$ RNA Select ${ }^{\mathrm{TM}}$ Green Fluorescent Cell Stain (Life Technology, S-32703). RNA was detected by bright green fluorescence $(\sim 490$ / $530 \mathrm{~nm}$ ) and the membranes were labeled with a red fluorescent cell stain $(\sim 589 / 617 \mathrm{~nm})$ for $20 \mathrm{~min}$ at $37^{\circ} \mathrm{C}$. Next, the medium was removed and the HPMCs were washed three times with PBS for confocal microscopy.

\subsection{Exosome authentication}

Three methods were used to identify exosomes, i.e., electron microscopy, Nanoparticle Tracking Analysis (NTA) and Western blotting. For electron microscopy, exosome pellets (see above) were re-suspended in PBS and dropped onto a carbon-coated copper electron microscope grid as previously described [18]. The exosomes were evaluated under a Tecnai G2 F20 ST transmission electron microscope. NTA was performed using ZetaView re-suspended in $500 \mu \mathrm{l}$ PBS. Exosome biomarkers were detected by Western blotting using antibodies directed against the tetraspanin molecule CD63 (Abcam, ab216130), CD9 (Abcam, ab92726), CD81 (Abcam, ab109201) and Tsg101 (Abcam, ab125011).

\subsection{Soluble protein analysis}

AEP, ITGA5 and ITGB1 levels were detected in sera and ascites samplers by ELISA using a Human Total Legumain DuoSet ELISA kit (R\&D Systems, DY4769), a Human Integrin $\alpha 5$ ELISA kit (R\&D Systems, DY1864-05) and a 
Human Integrin $\beta 1$ Antibody kit (R\&D Systems, MAB17784).

\subsection{Co-culture system and CCK8 assay}

For exosome and HPMC co-culture, SKOV3 exosomes were isolated as described above, and HPMCs were cultured in a 96-well plate (1500 cells/well). Exosomes were added daily to the HPMCs at $50 \mu \mathrm{g} / \mathrm{ml}$ culture medium. At 24, 48, 72, 96 and $120 \mathrm{~h}, 10 \mu \mathrm{l} \mathrm{CCK} 8$ solution (Beyotime, C0041) was added to each well and incubated for $2 \mathrm{~h}$ at $37{ }^{\circ} \mathrm{C}$. Absorption at $450 \mathrm{~nm}$ was measured using a microplate reader (Thermo Labsystems, Finland).

\subsection{Invasion assay}

Cell invasion was evaluated using a Transwell chamber $(8 \mu \mathrm{m}$ pore; Corning, 3422). To this end, cell suspensions $\left(6 \times 10^{4}\right.$ cells) in serum-free DMEM were added to the upper chamber with Matrigel (BD Biosciences, 356,234). DMEM containing $10 \%$ FBS was added to the bottom chamber. After $24 \mathrm{~h}$, the cells on the upper surface were removed and the cells that migrated to the lower surface were stained with $0.2 \%$ crystal violet for $10 \mathrm{~min}$. The cells were counted under a microscope (Olympus) using five random fields.

\subsection{In vivo experiment}

Female athymic nude mice (42; 6 weeks of age, 15-17 g) were purchased from Shanghai Slac Laboratory Animal Center and bred under SPF conditions in Tongji University School, Shanghai, China. The mice were randomly divided into 7 groups, and subjected to orthotopic injection with $10 \mu \mathrm{l}$ PBS containing $5 \times 10^{5}$ SKOV3-luc cells. Five of them were matched with the in vitro experiments, i.e., the SKOV3-WT group, the SKOV3-NC (for OE) group, the SKOV3-ITGASB1/AEP-OE group, the SKOV3-NC (for KD) group and the SKOV3-ITGASB1/ AEP-KD group. The other two groups were based on the SKOV3-ITGASB1/AEP-OE group, and AEP inhibitor [35] or dimethylamiloride (DMA) [36] were added every week. The tumors in the mice were examined for luciferin expression using D-luciferin $(100 \mathrm{mg} / \mathrm{kg}$, Invitrogen, Life Technologies, USA), and images were captured using a Night OWL IILB 983 instrument to assess tumor development every week. Image analyses were carried out using IndiGo software. All animal experiments were approved by the Medical Animal Care of Tongji University, and the animals were cared for according to the recommended use of laboratory animals.

\subsection{Statistics}

Data analyses were performed using SPSS version 20.0 statistical software (SPSS Inc., Chicago, IL). The results are presented as mean $\pm \mathrm{SEM}$. All experiments were repeated at least trice. The non-parametric test, the LSD test, Fisher's exact test and Levene's test (two-tailed) were used to determine $p$ values. Overall survival (OS) was calculated using the Kaplan-Meier method. Continuous variables in the figures are presented as mean $\pm \mathrm{SEM}$, and in the figures $*$ denotes a $p$ value $<0.05, * *$ denotes a $p$ value $<0.01$, *** denotes a $p$ value $<0.001$ and ${ }^{\#}$ denotes a $p$ value $>0.05$. A $p$ value $<0.05$ was considered statistically significant.

\subsection{Study approval}

The human studies and animal protocols were approved by the Institutional Review Board of Shanghai First Maternity and Infant Hospital. Written informed consent was obtained from all study participants or their guardians.

\section{Results}

\subsection{ITGA5B1 and AEP are highly expressed in EOC-HPMCs and co-localize in EOC cells and EOC-HPMCs}

HPMCs from EOC patients (EOC-HPMCs) were identified using immunohistochemistry and HE staining (Fig. $\mathrm{S} 1$ ). Integrin subtypes, including integrin $\alpha 4$ (ITGA4), integrin $\alpha 5$ (ITGA5), integrin $\alpha \mathrm{v}$ (ITGAv), integrin $\beta 1$ (ITGB1), integrin $\beta 3$ (ITGB3), integrin $\beta 4$ (ITGB4) and integrin $\beta 5$ (ITGB5), were assessed by Western blotting to compare EOC-HPMC and non EOC-HPMC subtypes (Fig. 1a). The integrin subtypes ITGA5 and ITGB1 showed the largest differences. In addition, we found that ITGA5B1 and AEP were expressed at higher levels in EOC-HPMCs than in non EOC-HPMCs (Fig. 1b). We calculated the gray values of each integrin subtype using GAPDH as an internal control (Fig. 1c). ITGA5B1 was found to be most abundant in all subtypes. In addition, we performed co-IP experiments revealing interaction of AEP with ITGA5B1 (Fig. 1d). HPMCs derived from 3 EOC patients were evaluated by immunofluorescence whereby fluorescence signals in different channels were superimposed. We found that ITGA5B1 was expressed in EOC-HPMCs (Fig. 1e) and EOC-derived SKOV3 cells (Fig. S2a), and that ITGA5B1 and AEP co-localized in the cytoplasm. 


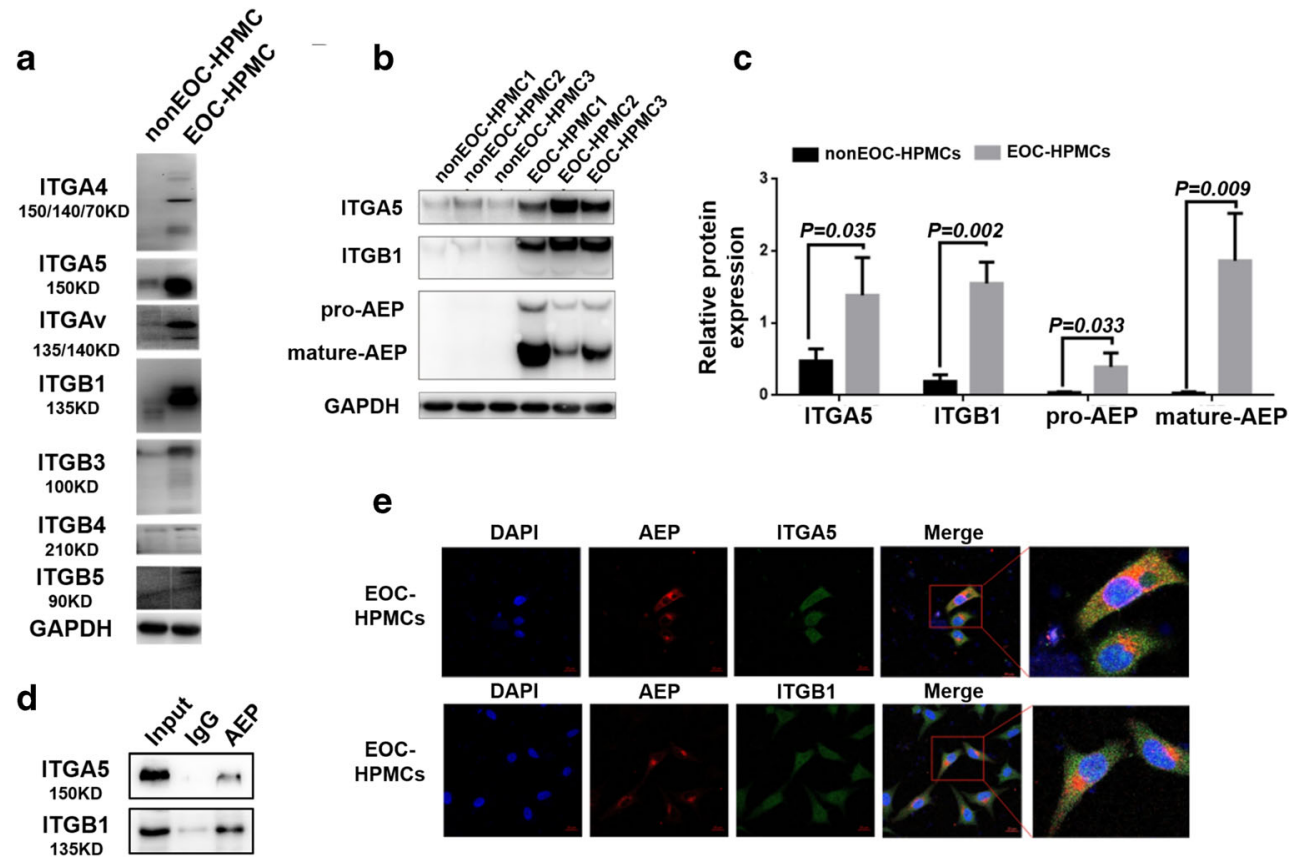

Fig. 1 ITGA5B1 and AEP are highly expressed in EOC-HPMCs and colocalize in EOCs and EOC-HPMCs. a Western blot analysis of integrin subtypes (ITGA4, ITGA5, ITGAv, ITGB1, ITGB3, ITGB4 and ITGB5) in non EOC-HPMCs and EOC-HPMCs. b Western blot analysis of ITGA5, ITGB1, pro-AEP and AEP proteins in non EOC-HPMCs and
EOC-HPMCs. c Gray values of Western blots were measured using ImageJ software. d Co-IP verifying the interaction of AEP with ITGA5B1. e Confocal microscopy images of AEP and ITGA5B1 colocalization in EOC-HPMCs. Scale bars, $20 \mu \mathrm{m}$ a

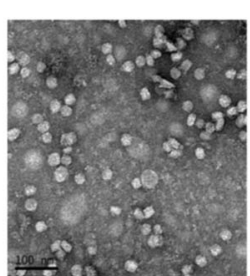

b

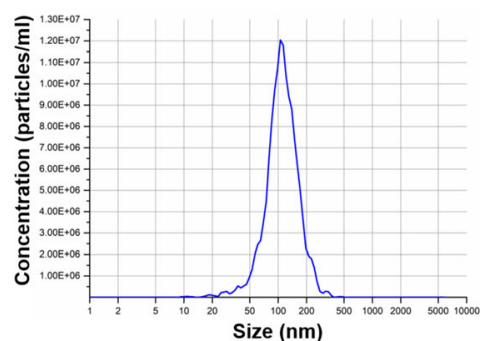

e

d

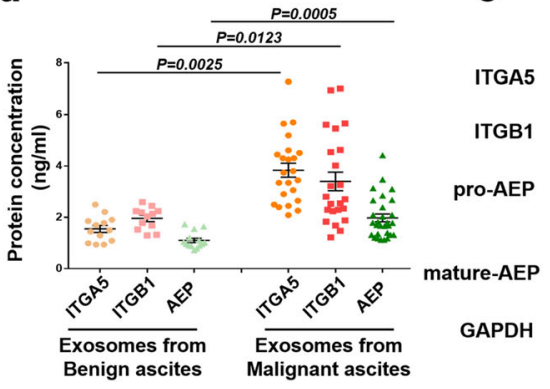

Fig. 2 ITGA5B1/AEP is overexpressed in serum and ascites exosomes from patients with EOC. a Representative transmission electron microscopy (TEM) micrograph of exosomes derived from ascites. Scale bar, $100 \mathrm{~nm}$. b NTA showing that the sizes of the exosomes range from $30 \mathrm{~nm}$ to $150 \mathrm{~nm}$. c Western blot analysis of Tsg101, CD9, CD63 and
C

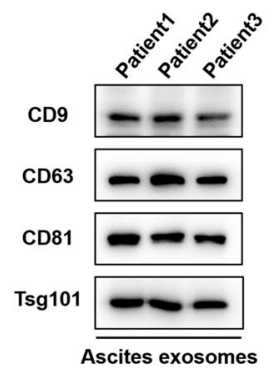

f

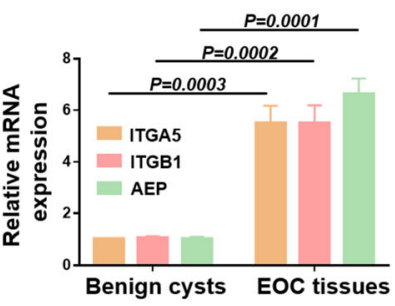

CD81 in exosomes derived from ascites. d Expression of AEP, ITGA5 and ITGB1 in exosomes derived from ascites of EOC patients and nonEOC patients analyzed by ELISA. $\mathbf{e}$ and $\mathbf{f}$ Western blot and quantitative RT-PCR analyses of ITGA5, ITGB1 and AEP expression in benign ovarian cysts and EOC tissues 
Fig. 3 The Exosomal ITGA5B1/ AEP complex secreted by EOC cells plays an important role in the proliferation and migration of HPMCs in vitro. a Unlabeled HPMCs were incubated with SKOV3-derived exosomes labeled with SytoRNA and D384. The DIC (differential interference contrast) presents the morphology of HPMCs that were not fluorescent. The data depict a typical image of 3 independent experiments. $\mathbf{b}$ and $\mathbf{c}$ Transfection efficiency of ITGA5, ITGB1 and AEP was detected by RT-PCR and Western blotting after establishing stable ITGA5B1/AEP-OE and ITGA5B1/AEP-KD SKOV3 cell lines. The data depict a typical image of 3 independent experiments. $\mathbf{d}$ and $\mathbf{e}$ Proliferation and migration capacities of HPMCs after incubation with exosomes derived from WT, NC (for OE), ITGA5B1/AEP-OE, NC (for KD) and ITGA5B1/AEP-KD cells using CCK8 and Transwell assays, respectively. f Crystal violet staining showing the migration of five groups. Typical images of three independent experiments are shown. Scale bar, $200 \mu \mathrm{m}$ a

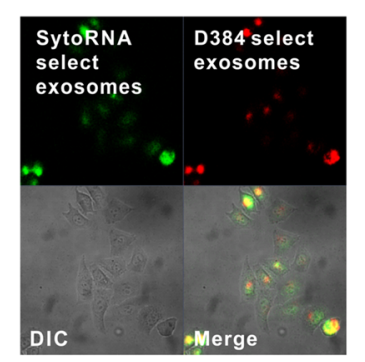

C

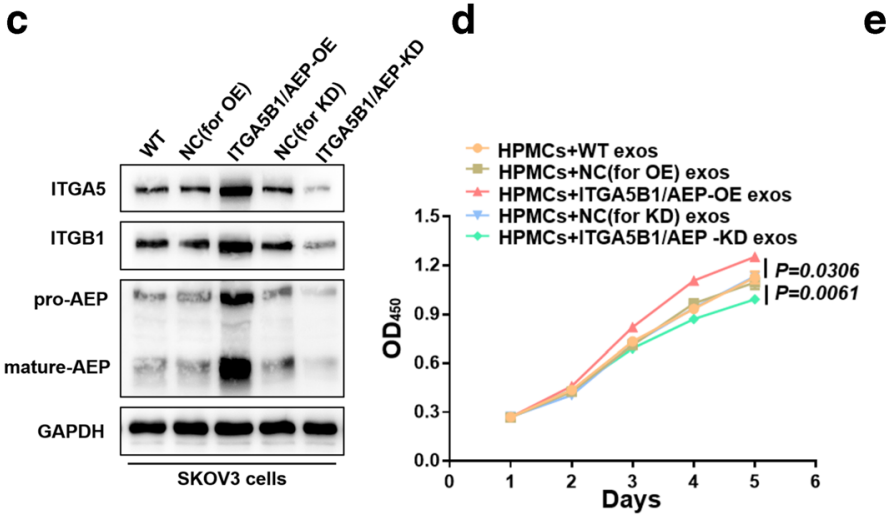

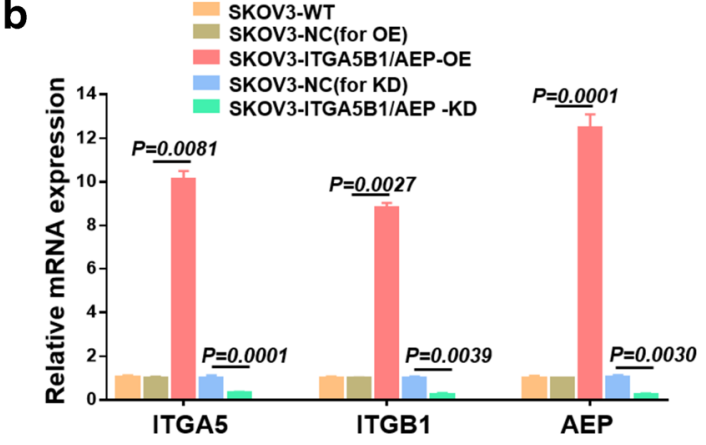

e

\section{$\mathbf{f}$}

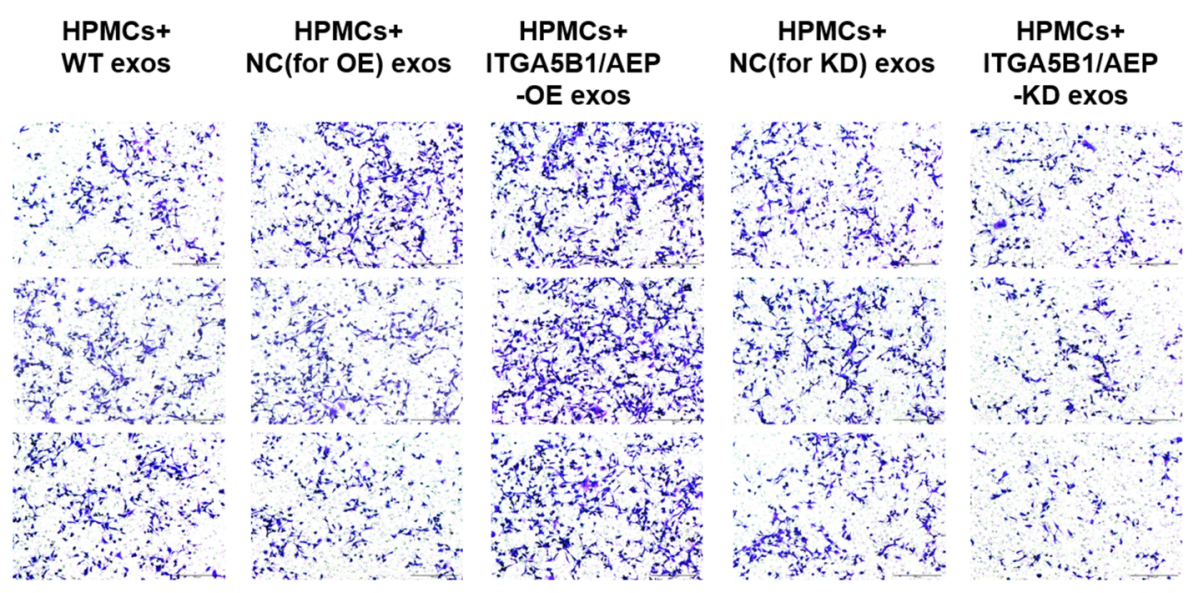

\subsection{ITGA5B1 complexes with AEP in EOC-HPMCs and is overexpressed in exosomes from sera and ascites from EOC patients}

We collected sera and ascites from benign ovarian tumor patients, hepatocirrhosis patients and EOC patients, and purified exosomes from them. The exosomes were identified by electron microscopy (Fig. 2a), and NTA (Fig. 2b) and the biomarkers Tsg101, CD9, CD63 and CD81 were detected by Western blotting (Fig. 2c). We found that the expression of AEP was higher in ascites exosomes derived from EOC patients (1.735 \pm $0.112 \mathrm{ng} / \mathrm{ml}$ ) than in those derived from benign ovarian tumor patients or hepatocirrhosis patients $(0.847 \pm$ $0.051 \mathrm{ng} / \mathrm{ml}, p=0.0005)$. The exosome integrins ITGA5 $(3.835 \pm 0.272 \mathrm{ng} / \mathrm{ml}$ to $1.548 \pm 0.139 \mathrm{ng} / \mathrm{ml}$, $p=0.0025)$ and ITGB1 $(3.401 \pm 0.363 \mathrm{ng} / \mathrm{ml}$ to 1.958 $\pm 0.125 \mathrm{ng} / \mathrm{ml}, p=0.0123$ ) in ascites showed the same trend as AEP (Fig. 2d). The expression of ITGA5, ITGB1 and AEP was also higher in serum exosomes derived from EOC patients than in those derived from benign ovarian tumor patients (Fig. S2b). In addition, we found that total ITGA5, ITGB1 and AEP levels in ascites from EOC patients showed no significant differences from those in ascites from benign ovarian tumor patients or hepatocirrhosis patients (Fig. S2c). These 
a

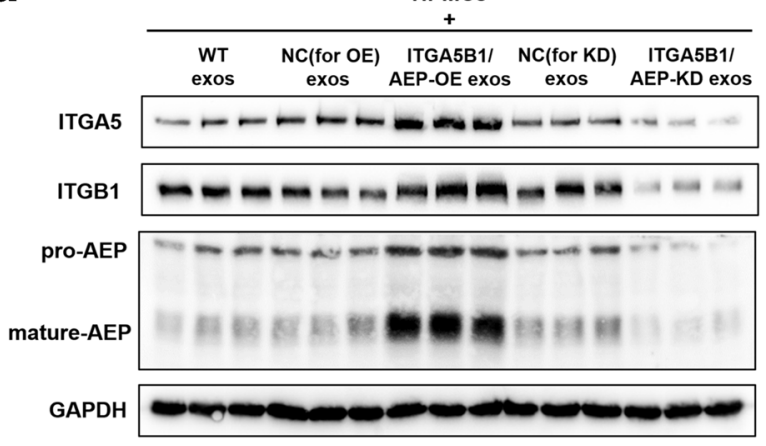

C

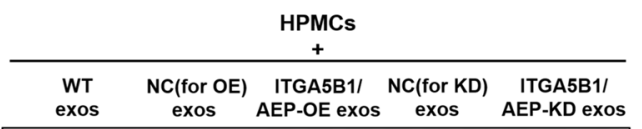

FAK

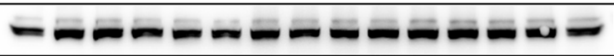

$\operatorname{P-FAK(Tyr397)~}-\ldots-\ldots-\ldots-\ldots-\cdots$

Akt $\quad 0-\infty-\infty-\infty-\infty-\infty$
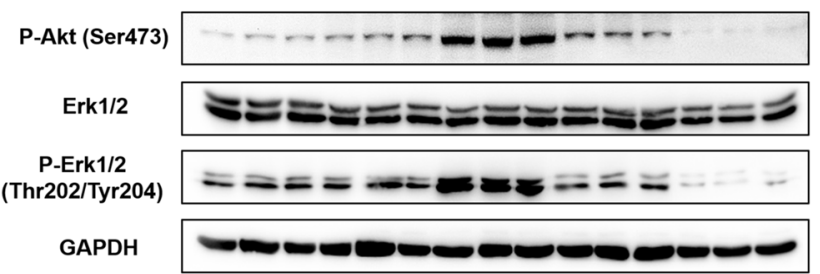

e

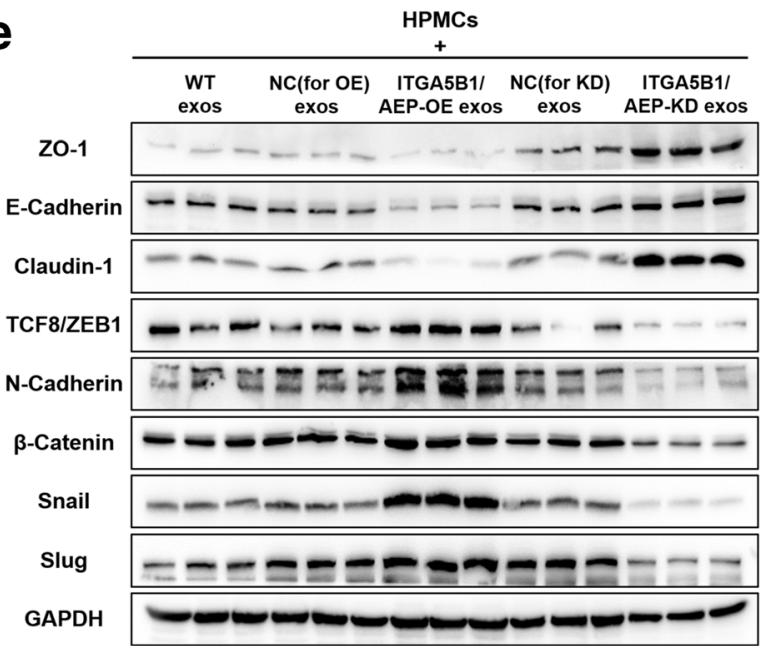

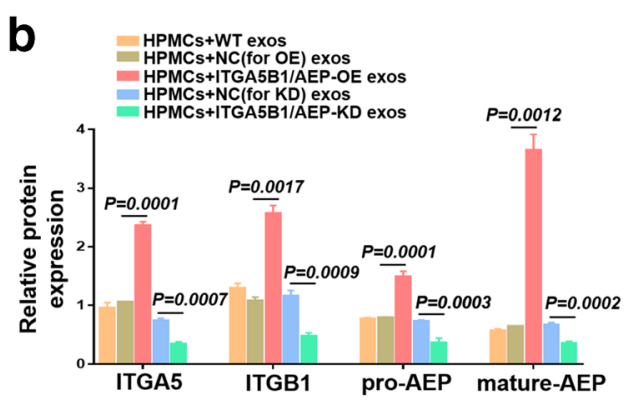
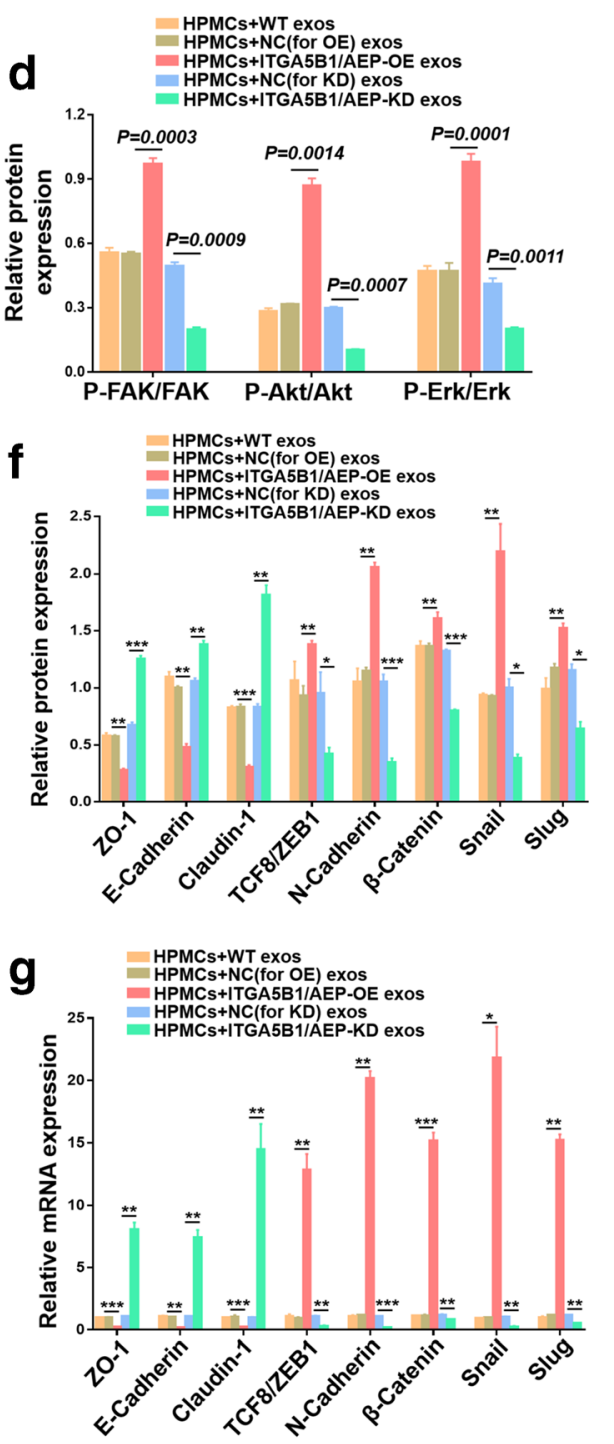

Fig. 4 HPMCs undergo downstream FAK/Akt/Erk pathway changes and EMT after co-culture with EOC exosomes. $\mathbf{a}$ and $\mathbf{b}$ Western blot and gray value analyses showing ITGA5, ITGB1 and AEP expression in HPMCs after co-culture with WT exosomes, NC (for OE) exosomes, ITGA5B1/ AEP-OE exosomes, NC (for KD) exosomes and ITGA5B1/AEP-KD exosomes. $\mathbf{c}$ and $\mathbf{d}$ Western blot and gray value analyses showing FAK,
P-FAK, Akt, P-Akt, Erk and P-Erk expression in the five different groups. $\mathbf{e}$ and $\mathbf{f}$ Western blot and gray value analyses showing the EMT markers ZO-1, E-cadherin, claudin-1, ZEB1, N-cadherin, $\beta$-catenin, Snail and Slug. g RT-PCR analysis showing mRNA levels of EMT markers. All data presented are representative of three independent experiments

cysts, EOC tissues showed higher ITGA5, ITGB1 and AEP levels (Fig. 2e and f), which may be the source of exosomal ITGA5B1/AEP in malignant ascites and malignant serum. 
Fig. 5 Inhibition of exosomal secretion or ITGA5B1/AEP function decreases peritoneal metastasis and overall survival in vivo. a Typical images of tumor flux (cps) at week 6 are presented. b After euthanasia, the tumor tissues were removed and presented. $\mathbf{c}$ The tumor flux of different groups recorded by bioluminescence imaging is presented. d Tumor weights of different groups. e Immunohistochemical staining performed on peritoneal metastases in mice of different groups. Scale bar, $20 \mu \mathrm{m}$. f Western blot analysis showing the expression of ITGA5, ITGB1 and AEP in peritoneal metastasis and corresponding peri-metastasis tissues a
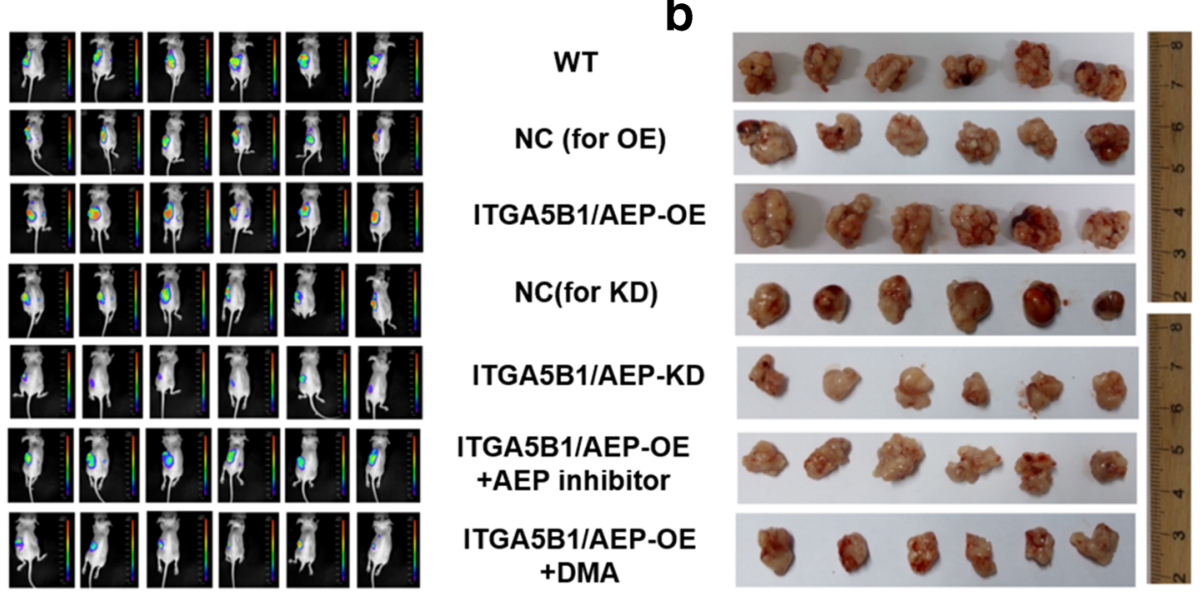

C

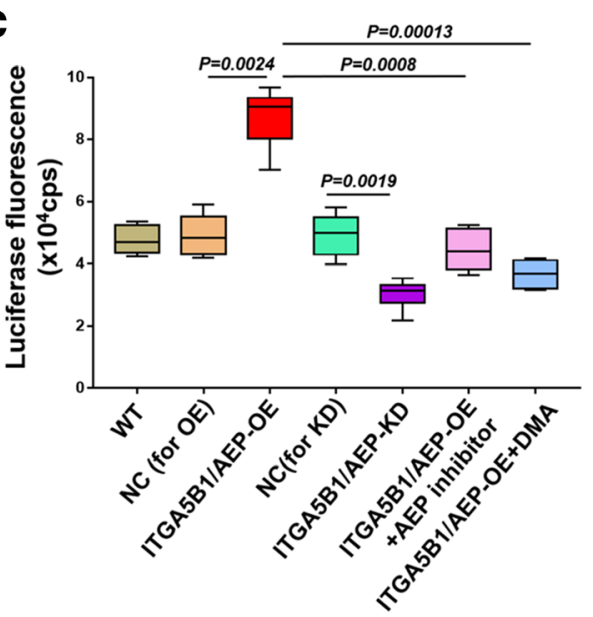

e

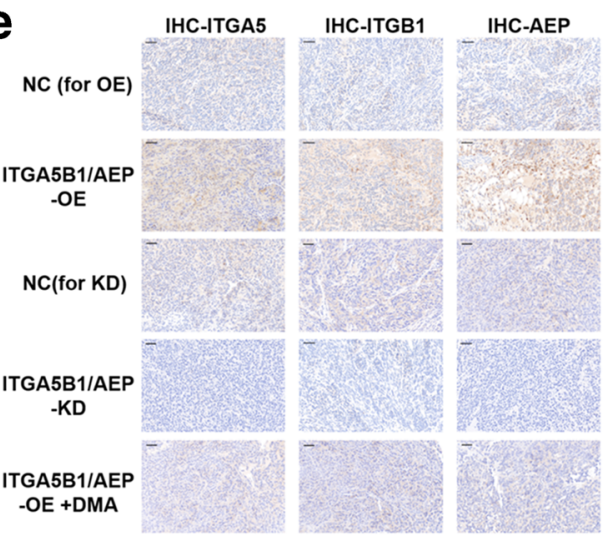

d

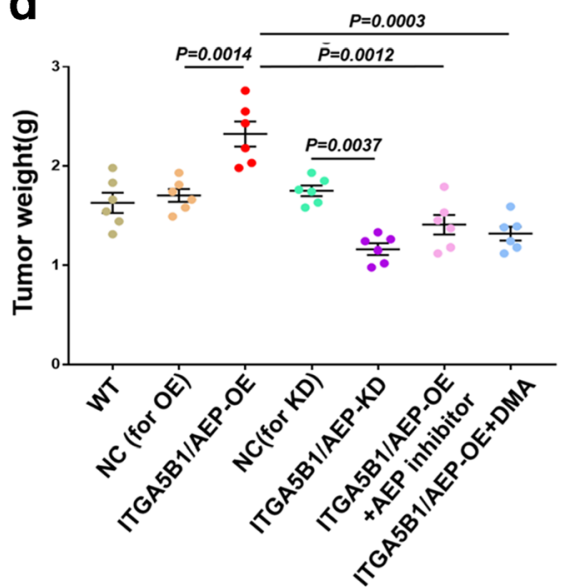

f

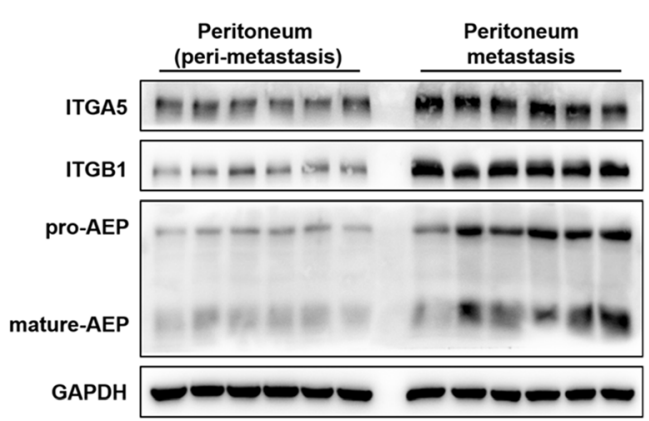

\subsection{The exosomal ITGA5B1/AEP complex secreted by EOC cells affects the proliferation and migration of HPMCs}

We used immunofluorescence to verify whether exosomes are taken up by HPMCs. RNAs (green) and membranes (red) of exosomes in HPMCs were evaluated using confocal microscopy (Fig. 3a). Next, we used lentiviral vectors to establish stable ITGASB1/AEP-overexpressing (OE) and ITGA5B1/ AEP-knockdown (KD) SKOV3 cell lines. The expression level of ITGA5B1/AEP was detected by quantitative RTPCR (Fig. 3b) and Western blotting (Fig. 3c). To determine whether the exosomal ITGA5B1/AEP complex is crucial for HPMC proliferation and migration, we collected exosomes from SKOV3-WT, SKOV3-NC (for OE), SKOV3ITGA5B1/AEP-OE, SKOV3-NC (for KD) and SKOV3ITGA5B1/AEP-KD cells. These exosomes were subsequently co-cultured with HPMCs. The results showed that the proliferation rate of HPMCs treated with exosomes from ITGA5B1/ AEP-KD cells was lower than that of HPMCs treated with 
Table 1 Number of tumor metastases in an orthotopic model of ovarian cancer $(n=6)$

\begin{tabular}{|c|c|c|c|c|c|c|c|}
\hline Group & Peritoneal metastases & Spleen & Liver & Stomach & Pancreas & Lymph nodes & Ascites \\
\hline SKOV3-WT & $2 / 6$ & $2 / 6$ & $1 / 6$ & $2 / 6$ & $1 / 6$ & $1 / 6$ & $2 / 6$ \\
\hline SKOV3-NC (for OE) & $1 / 6$ & $3 / 6$ & $2 / 6$ & $1 / 6$ & $1 / 6$ & $1 / 6$ & $1 / 6$ \\
\hline SKOV3-ITGA5B1/AEP-OE & $4 / 6$ & $5 / 6$ & $3 / 6$ & $3 / 6$ & $3 / 6$ & $2 / 6$ & $3 / 6$ \\
\hline SKOV3-NC (for KD) & $2 / 6$ & $1 / 6$ & $3 / 6$ & $2 / 6$ & $1 / 6$ & $1 / 6$ & $1 / 6$ \\
\hline SKOV3-ITGA5B1/AEP-KD & $2 / 6$ & $1 / 6$ & $1 / 6$ & $1 / 6$ & $1 / 6$ & $1 / 6$ & $1 / 6$ \\
\hline SKOV3-ITGA5B1/AEP-OE+AEP inhibitor & $2 / 6$ & $2 / 6$ & $0 / 6$ & $1 / 6$ & $1 / 6$ & $0 / 6$ & $0 / 6$ \\
\hline SKOV3-ITGA5B1/AEP-OE+DMA & $1 / 6$ & $1 / 6$ & $0 / 6$ & $0 / 6$ & $0 / 6$ & $0 / 6$ & $1 / 6$ \\
\hline
\end{tabular}

exosomes from NC (for KD) cells ( $p=0.0061$, Fig. $3 \mathrm{~d}$ ). In contrast, we found that HPMCs treated with exosomes from ITGA5B1/AEP-OE cells grew faster than those treated with exosomes from NC (for OE) cells ( $p=0.0306$, Fig. $3 \mathrm{~d}$ ). Similarly, the migration capacity of HPMCs treated with exosomes from ITGA5B1/AEP-KD cells was found to be lower than that of HPMCs treated with exosomes from $\mathrm{NC}$ (for $\mathrm{KD}$ ) cells $(p=0.0014$, Fig. 3e). The opposite tendency was noted in ITGA5B1/AEP-OE exosomes and NC (for OE) exosomes ( $p=0.0024$, Fig. 3e). Crystal violet staining depicted the migration abilities of the five groups (Fig. 3f). Taken together, these data indicate that the exosomal ITGA5B1/AEP complex secreted by EOC cells affects the proliferation and migration of HPMCs in vitro.

\subsection{HPMCs undergo ITGA5B1/AEP downstream FAK/Akt/Erk pathway changes and EMT after co-culture with EOC-derived exosomes}

To assess changes in downstream pathways after exosomal ITGA5B1/AEP transfer to HPMCs, we collected HPMCs co-cultured with five different EOC-derived exosomes, namely WT exosomes, NC (for OE) exosomes, ITGA5B1/AEP-OE exosomes, $\mathrm{NC}$ (for KD) exosomes and ITGA5B1/AEP-KD exosomes. Using Western blotting we found that the HPMCs exhibited higher ITGA5, ITGB1 and AEP expression levels after co-culture with ITGA5B1/AEP-OE exosomes, and that those after coculture with ITGA5B1/AEP-KD exosomes showed the opposite effect (Fig. 4a). The gray values of each blot were used to reflect the relative content (Fig. 4b). Next, we found that the proliferation and migration-related FAK/Akt/Erk pathways [37, 38] showed no changes in total FAK, Akt and Erk levels, but that the phosphorylation levels of each protein in the ITGA5B1/AEP-OE exosomes group increased, whereas they decreased in the ITGA5B1/AEP-KD exosomes group (Fig. 4c and d). In addition, we found that the levels of proteins involved in EMT, and the epithelial markers ZO-1, E-cadherin and claudin-1, were decreased in the ITGA5B1/AEP-KD exosomes group, but increased in the ITGA5B1/AEP-OE exosomes group. At the same time, we found that the mesenchyme-related proteins ZEB1, N-cadherin, $\beta$-catenin, Snail and Slug showed the opposite trend (Fig. 4e and f). Finally, quantitative RT-PCR revealed that the respective mRNA levels showed the same trend as the protein levels (Fig. 4g).

\subsection{Inhibiting exosome secretion or ITGA5B1/AEP complex function decreases peritoneal metastasis and overall survival in vivo}

To investigate the role of the ITGA5B1/AEP complex in EOC peritoneal metastasis in vivo, different groups were denoted according to the different dispositions, i.e., SKOV3-WT group, SKOV3-NC (for OE) group, SKOV3-ITGA5B1/ AEP-OE group, SKOV3-NC (for KD) group, SKOV3ITGA5B1/AEP-KD group, SKOV3-ITGA5B1/AEP-OE + AEP inhibitor group and SKOV3-ITGA5B1/AEP-OE + DMA group. After orthotopic injecting different SKOV3-luc cells in nude mice, we used a bioluminescence imaging system to assess tumor growth. The tumor flux (cps) was recorded every week, and typical images at week 6 are presented (Fig. 5a). The ITGA5B1/AEP-OE group $\left(8.732 \pm 0.384 \times 10^{4}\right.$ cps) led to an enhancement in total tumor flux compared to that of the NC (for OE) group $\left(4.917 \pm 0.263 \times 10^{4} \mathrm{cps}\right)$, the ITGA5B1/AEP-OE + AEP inhibitor group $(4.440 \pm 0.259 \times$ $\left.10^{4} \mathrm{cps}\right)$ or the ITGA5B1/AEP-OE + DMA group $(3.670 \pm$ $\left.0.195 \times 10^{4} \mathrm{cps}\right)$. The ITGA5B1/AEP-KD group $(3.032 \pm$ $0.189 \times 10^{4} \mathrm{cps}$ ) showed reduced tumor growth (Fig. 5c). These results were in conformity with the tumor weight (Fig. 4d) and tumor volume (Supplemental Table S1) results.

After euthanasia, the tumor tissues were removed (Fig. 5b) and found to be accompanied by metastases to the peritoneum, spleen, liver, stomach, pancreas, lymph nodes and ascites (Table 1). More tumor metastases were observed in the ITGA5B1/AEP-OE group than in the other six groups. Immunohistochemical staining was performed on peritoneal metastases in the different groups (Fig. 5e). The peritoneal metastases and the corresponding perimetastasis tissues were collected for Western blot analysis. We found that the expression of ITGA5, ITGB1 and AEP 
Fig. 6 High expression of ITGA5B1/AEP in EOC primary tissues and metastatic tissues is negatively associated with overall survival. a Representative immunohistochemistry (IHC) staining of the AEP protein in EOC tissues $(n=153)$, benign ovarian tumor tissues $(n=81)$, benign peritoneum tissues $(n=14)$ and peritoneal metastasis tissues $(n=15)$. $\mathbf{b}$ and c An IRS scoring system was used to evaluate the expressions of AEP, ITGA5 and ITGB1. d EOC patients with a high ITGA5B1/AEP expression exhibited a significantly lower overall survival a

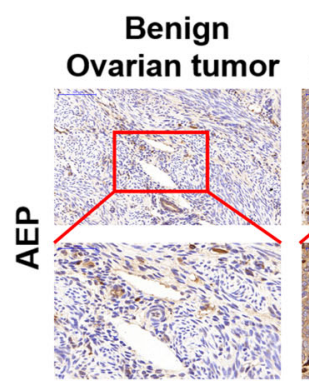

Malignant Ovarian tumor

Benign Peritoneum
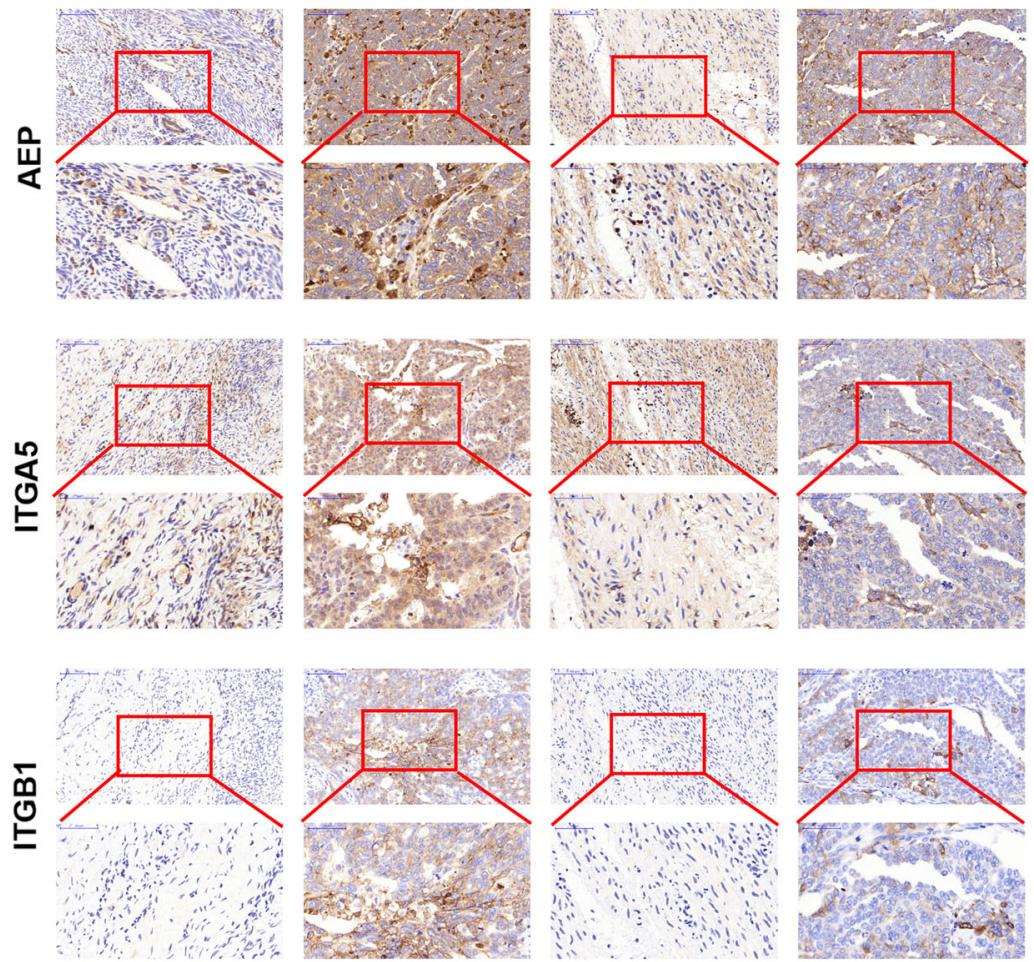

b
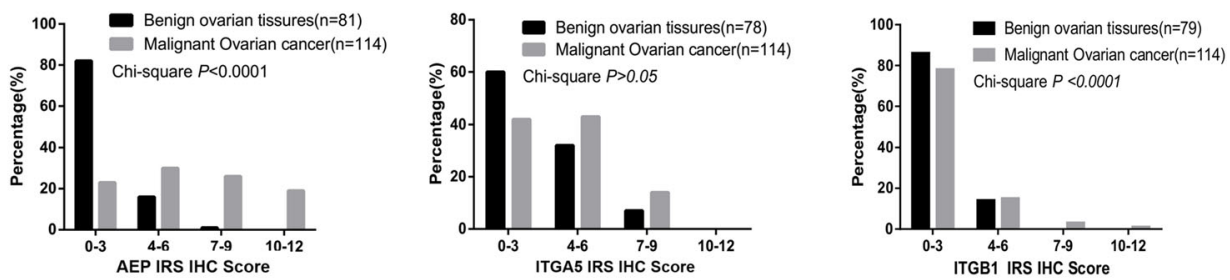

C
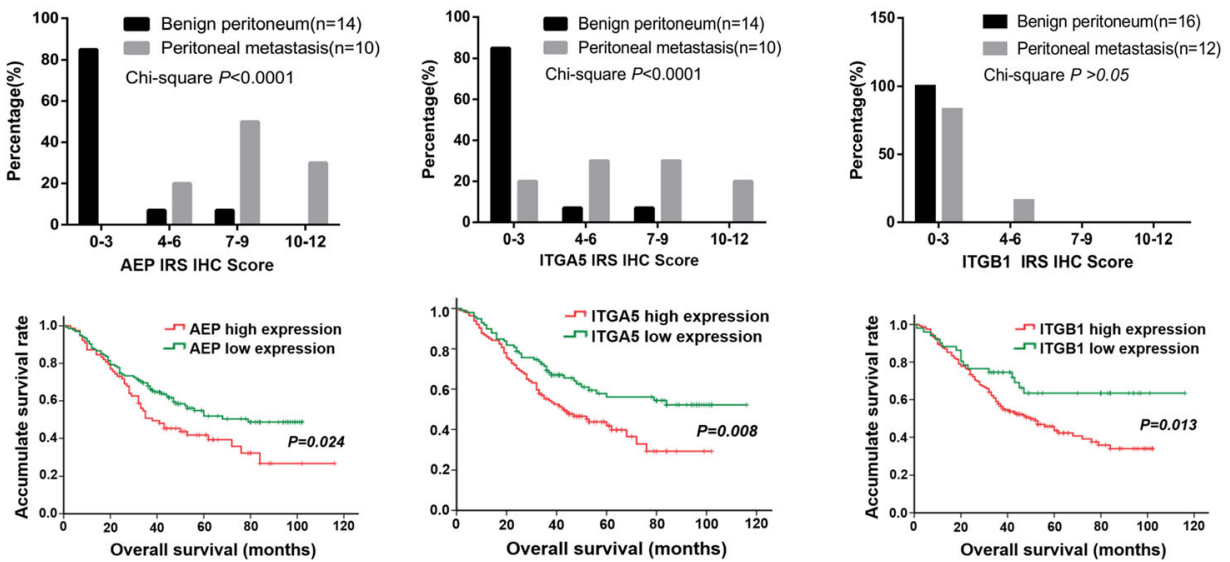

in the peritoneal metastases was significantly higher (Fig. 5f). Together, these data indicate that the exosome ITGA5B1/AEP complex promotes peritoneal metastasis of EOC in vivo, and that inhibition of exosome secretion or ITGA5B1/AEP complex function may decrease EOC peritoneal metastasis.

\subsection{Expression of the ITGA5B1/AEP complex in clinical specimens is associated with EOC progression and metastasis}

To assess the expression pattern of the ITGA5B1/AEP complex, 81 benign ovarian tumor tissues, 14 benign peritoneal 
Table 2 Univariate analyses of OS in 153 EOC patients

\begin{tabular}{|c|c|c|c|}
\hline Variables & $\mathrm{N}$ & $\begin{array}{l}\text { Overall survival (OS) univariate analysis } \\
(\text { Mean } \pm \text { SEM) }\end{array}$ & $p$ value \\
\hline \multicolumn{4}{|l|}{ Age } \\
\hline$<50$ & 67 & $46.45 \pm 2.92$ & \multirow[t]{2}{*}{0.153} \\
\hline$\geq 50$ & 86 & $45.71 \pm 2.43$ & \\
\hline \multicolumn{4}{|c|}{ Clinical stage } \\
\hline $\mathrm{I}+\mathrm{II}$ & 38 & $65.04 \pm 4.47$ & \multirow[t]{2}{*}{$<0.001$} \\
\hline III + IV & 115 & $39.51 \pm 1.85$ & \\
\hline \multicolumn{4}{|c|}{ Histological subtype } \\
\hline SOC & 131 & $42.40 \pm 1.95$ & \multirow[t]{2}{*}{0.005} \\
\hline NSOC & 22 & $59.77 \pm 5.36$ & \\
\hline \multicolumn{4}{|c|}{ Histological grade } \\
\hline Low & 47 & $60.42 \pm 4.11$ & \multirow[t]{2}{*}{0.001} \\
\hline High & 106 & $39.71 \pm 1.93$ & \\
\hline
\end{tabular}

tissues, 114 EOC tissues and 10 peritoneal metastatic tissues were evaluated by immunohistochemistry. To evaluate ITGA5B1/AEP complex expression, we used the IRS scoring system $($ IRS $=$ Staining Intensity $(\mathrm{SI}) \times$ Percentage of Positive cells (PP)) [31]. In doing so, we found that the expression of AEP was higher in EOC and peritoneal metastatic tissues than in benign ovarian tumor and benign peritoneal tissues (Fig. 6a-c). Similar results were obtained for ITGA5 and ITGB1 (Fig. 6a-c). Together, these data suggest that a high expression of the ITGA5B1/AEP complex may be associated with EOC progression and metastasis. Clinical characteristics of the EOC patients and univariate analyses of overall survival rates are listed in Table 2. EOC patients with a high expression of the ITGA5B1/AEP complex exhibited a significantly lower overall survival rate than patients with a low expression of the ITGA5B1/AEP complex (Fig. 6d).

\section{Discussion}

Integrins are known to regulate cell-cell and cell-matrix interactions and it has amply been reported that integrins may be involved in tumor progression and metastasis [39-41]. According to the "seed-and-soil" hypothesis, metastatic organotropism is one of the characteristics of cancer [42]. Exosome proteomics revealed distinct integrin expression patterns, such as those of the integrins $\alpha 6 \beta 4$ and $\alpha 6 \beta 1$, which have been associated with lung metastasis, whereas that of integrin $\alpha \mathrm{v} \beta 5$ has been linked to liver metastasis [43]. Integrin functions may thus vary with its different subunits, and it is therefore important to consider integrin subtypes when exploring their effects in different cancers [16-18]. In this study, we isolated HPMCs from EOC patients and assessed integrin subtypes. We found that ITGA5B1was
Fig. 7 Diagram illustrating our conclusions. EOC cells transfer exosomes that are enriched in ITGA5B1/AEP to HPMCs, and these exosomes promote the proliferation and migration of HPMCs. In addition, HPMCs undergo phosphorylation of the FAK/Akt/Erk pathway as well as EMT, ultimately favoring EOC peritoneal metastasis

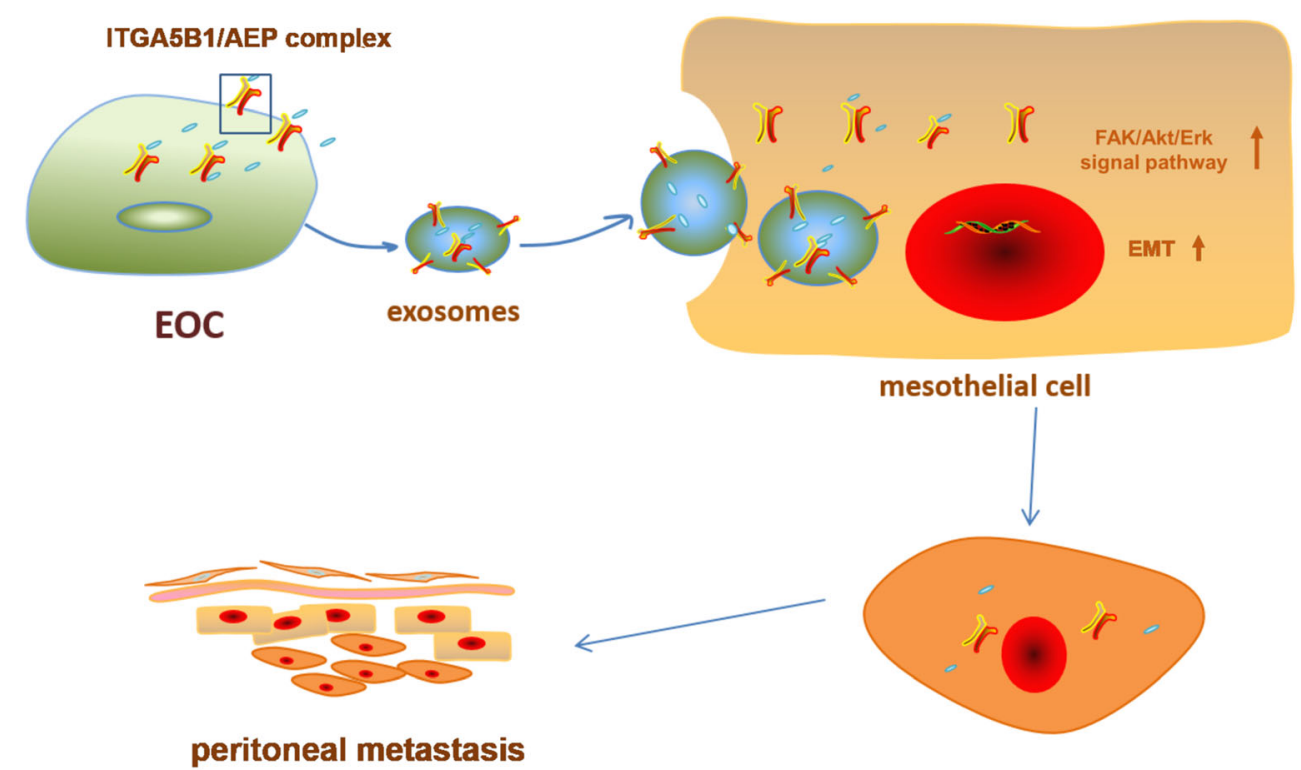


highly expressed in HPMCs from EOC patients. More importantly, we found using immunofluorescence confocal microscopy that ITGA5B1 co-localized with AEP in HPMCs from EOC patients.

AEP, also known as legumain, is synthesized as a zymogen-like endosomal protease, and AEP can undergo auto-proteolytic maturation under acidic $\mathrm{pH}$ conditions to catalytic activation. In addition, AEP has been found to be predominantly localized in late endosomes and lysosomes [44, 45]. More recently, AEP has been reported to regulate innate immune responses via its participation in the maturation of toll-like receptors (TLRs) [46]. Others found that AEP was highly expressed on the surface of tumorassociated macrophages (TAMs), and that these $\mathrm{AEP}^{+}$ TAMs play a critical role in promoting tumor development and angiogenesis. Targeting AEP on TAMs may, therefore, represent a novel anticancer strategy $[47,48]$. AEP expression has also been found to be related to clinicopathologic and biological variables in colorectal cancer [49]. So far, however, the relationship between ITGA5B1 and AEP expression in EOC has remained unknown. In 2003 it was reported that AEP may co-localized with integrins [50]. In the present study, we found that both high ITGA5B1 and AEP levels were found in exosomes derived from sera and ascites of EOC patients. The mechanism underlying exosomal ITGA5B1/AEP complex EOC peritoneal metastasis promotion warrants further discussion.

Exosomes are known to contain microRNAs, mRNAs and proteins, to be released from normal cells and cancer cells and to play important roles in cell-to-cell communication [51, 52]. To explore the functional role of the exosomal ITGA5B1/AEP complex, we established stable AEP-KD SKOV3 cell lines, and confirmed that suppression of the exosomal ITGA5B1/ AEP complex reduced HPMC proliferation and migration. Conversely, we found that the exosomal ITGA5B1/AEP complex from AEP-OE SKOV3 cells could promote HPMC proliferation and migration. Finally, we found using primary clinical samples that the ITGA5B1/AEP complex was highly expressed in exosomes derived from sera and ascites of patients with EOC. Our results also indicated that tumor-derived exosomes taken up by organ-specific cells may prepare the pre-metastatic niche [43], which in turn may explain the mechanism underlying peritoneal EOC metastasis.

Our data provide new insights into how the exosomal ITGA5B1/AEP complex may promote HPMC proliferation and migration both in vivo and in vitro. We found that HPMCs underwent downstream FAK/Akt/Erk pathway changes and EMT after co-culture with EOC-derived exosomes. A putative HPMC feedback on cancer cells requires, however, further investigation. Data retrieved from clinical specimens indicated that ITGA5B1 and AEP were overexpressed in both primary EOC tissues and metastatic lesions, and that high ITGA5B1/AEP levels were associated with a poor prognosis. As such, the ITGA5B1/AEP complex may serve as a prognostic factor in EOC patients.

In conclusion, our data indicate that the exosomal ITGA5B1/AEP complex derived from EOCs may promote the proliferation and migration in HPMCs through regulating the FAK/Akt/Erk pathway as well as EMT, ultimately resulting in peritoneal metastasis (Fig. 7). These exosomes and the ITGA5B1/AEP complex may serve as prognostic factors and/or potential therapeutic targets for EOC.

Acknowledgements The authors thank Shanghai First Maternity and Infant Hospital for providing patient specimens.

Funding This study was supported by grants from the National Science Foundation of China $(81402042$, 81602280, 81772654, 81874103, 81930064), the Shanghai Municipal Health Bureau (20154Y0109), the Shanghai Science and Technology Development Foundation (17411968100) and the training plan for scientific research of Renji Hospital (RJZZ13-021).

\section{Compliance with ethical standards}

Conflict of interest The authors have declared that no conflict of interest exists.

Open Access This article is licensed under a Creative Commons Attribution 4.0 International License, which permits use, sharing, adaptation, distribution and reproduction in any medium or format, as long as you give appropriate credit to the original author(s) and the source, provide a link to the Creative Commons licence, and indicate if changes were made. The images or other third party material in this article are included in the article's Creative Commons licence, unless indicated otherwise in a credit line to the material. If material is not included in the article's Creative Commons licence and your intended use is not permitted by statutory regulation or exceeds the permitted use, you will need to obtain permission directly from the copyright holder. To view a copy of this licence, visit http://creativecommons.org/licenses/by/4.0/.

\section{References}

1. R.L. Siegel, K.D. Miller, A. Jemal, Cancer statistics, 2016. CA Cancer J Clin 66, 7-30 (2016)

2. W.G. Mccluggage, Morphological subtypes of ovarian carcinoma: A review with emphasis on new developments and pathogenesis. Pathology 43, 420-432 (2011)

3. R.L. Coleman, B.J. Monk, A.K. Sood, T.J. Herzog, Latest research and treatment of advanced-stage epithelial ovarian cancer. Nat Rev Clin Oncol 10, 211-224 (2013)

4. N.S. Horowitz, A. Miller, B. Rungruang, S.D. Richard, N. Rodriguez, M.A. Bookman, C.A. Hamilton, T.C. Krivak, G.L. Maxwell, Does aggressive surgery improve outcomes? Interaction between preoperative disease burden and complex surgery in patients with advanced-stage ovarian cancer: An analysis of GOG 182. J Clin Oncol 33, 937-943 (2015)

5. K. Gasimli, E.I. Braicu, R. Richter, R. Chekerov, J. Sehouli, Prognostic and predictive value of the peritoneal cancer index in primary advanced epithelial ovarian cancer patients after complete cytoreductive surgery: Study of tumor bank ovarian cancer. Ann Surg Oncol 22, 2729-2737 (2015) 
6. H. Naora, D.J. Montell, Ovarian cancer metastasis: Integrating insights from disparate model organisms. Nat Rev Cancer 5, 355-366 (2005)

7. C. Theriault, M. Pinard, M. Comamala, M. Migneault, J. Beaudin, I. Matte, M. Boivin, A. Piche, C. Rancourt, MUC16 (CA125) regulates epithelial ovarian cancer cell growth, tumorigenesis and metastasis. Gynecol Oncol 121, 434-443 (2011)

8. A.M. Nick, R.L. Coleman, P.T. Ramirez, A.K. Sood, A framework for a personalized surgical approach to ovarian cancer. Nat Rev Clin Oncol 12, 239-245 (2015)

9. J.O. Schorge, C. Mccann, M.G. Del Carmen, Surgical debulking of ovarian cancer: What difference does it make? Rev Obstet Gynecol 3, 111-117 (2010)

10. N. Ahmed, K.L. Stenvers, Getting to know ovarian Cancer ascites: Opportunities for targeted therapy-based translational research. Front Oncol 3, 1-9 (2013)

11. J. Greenaway, R. Moorehead, P. Shaw, J. Petrik, Epithelial-stromal interaction increases cell proliferation, survival and tumorigenicity in a mouse model of human epithelial ovarian cancer. Gynecol Oncol 108, 385-394 (2008)

12. M. Nakamura, Y.J. Ono, M. Kanemura, T. Tanaka, M. Hayashi, Y. Terai, M. Ohmichi, Hepatocyte growth factor secreted by ovarian cancer cells stimulates peritoneal implantation via the mesothelialmesenchymal transition of the peritoneum. Gynecol Oncol 139, 345-354 (2015)

13. T. Brabletz, R. Kalluri, M.A. Nieto, R.A. Weinberg, EMT in cancer. Nat Rev Cancer 18, 128-134 (2018)

14. M.P. Iwanicki, R.A. Davidowitz, R.N. Mei, A. Besser, T. Muranen, M. Merritt, G. Danuser, I. Tan, J.S. Brugge, Ovarian cancer spheroids use myosin-generated force to clear the mesothelium. Cancer Discov 1, 144-157 (2011)

15. N.D. Franceschi, H. Hamidi, J. Alanko, P. Sahgal, J. Ivaska, Integrin traffic - The update. J Cell Sci 128, 839-852 (2015)

16. D. Naci, K. Vuori, F. Aoudjit, Alpha2beta1 integrin in cancer development and chemoresistance. Semin Cancer Biol 35, 145-153 (2015)

17. J. Gao, Z. Hu, D. Liu, J. Liu, C. Liu, R. Hou, S. Gao, D. Zhang, S. Zhang, B. Lin, Expression of Lewis y antigen and integrin $\alpha v, \beta 3$ in ovarian cancer and their relationship with chemotherapeutic drug resistance. J Exp Clin Cancer Res 32, 36-48 (2013)

18. B. Deng, S. Zhang, Y. Miao, Z. Han, X. Zhang, F. Wen, Y. Zhang, Adrenomedullin expression in epithelial ovarian cancers and promotes HO8910 cell migration associated with upregulating integrin $\alpha 5 \beta 1$ and phosphorylating FAK and paxillin. J Exp Clin Cancer Res 31, 19-28 (2012)

19. E. Shinderman-Maman, K. Cohen, C. Weingarten, D. Nabriski, O. Twito, L. Baraf, A. Hercbergs, P.J. Davis, H. Werner, M. Ellis, O. Ashur-Fabian, The thyroid hormone- $\alpha \mathrm{v} \beta 3$ integrin axis in ovarian cancer: Regulation of gene transcription and MAPK-dependent proliferation. Oncogene 35, 1977-1987 (2016)

20. T. Strobel, S.A. Cannistra, Beta1-integrins partly mediate binding of ovarian cancer cells to peritoneal mesothelium in vitro. Gynecol Oncol 73, 362-367 (1999)

21. D.N. Li, S.P. Matthews, A.N. Antoniou, D. Mazzeo, C. Watts, Multistep autoactivation of asparaginyl endopeptidase in vitro and in vivo. J Biol Chem 278, 38980-38990 (2003)

22. G. Basurtoislas, I. Grundkeiqbal, Y.C. Tung, F. Liu, K. Iqbal, Activation of asparaginyl endopeptidase leads to tau hyperphosphorylation in Alzheimer disease. J Biol Chem 288, 17495-17507 (2013)

23. F.E. Sepulveda, S. Maschalidi, R. Colisson, L. Heslop, C. Ghirelli, E. Sakka, A.M. Lennondumenil, S. Amigorena, L. Cabanie, B. Manoury, Critical role for asparagine endopeptidase in endocytic toll-like receptor signaling in dendritic cells. Immunity 31, 737-748 (2009)
24. Y. Lin, Y. Qiu, C. Xu, Q. Liu, B. Peng, G.F. Kaufmann, X. Chen, B. Lan, C. Wei, D. Lu, Y. Zhang, Y. Guo, Z. Lu, B. Jiang, T. Edgington, F. Guo, Functional role of asparaginyl endopeptidase ubiquitination by TRAF6 in tumor invasion and metastasis. J Natl Cancer Inst 106, 12-21 (2014)

25. Y. Ohno, J. Nakashima, M. Izumi, M. Ohori, T. Hashimoto, M. Tachibana, Association of legumain expression pattern with prostate cancer invasiveness and aggressiveness. World J Urol 31, 359$364(2013)$

26. M.H. Haugen, K. Boye, J.M. Nesland, S.J. Pettersen, E.V. Egeland, T. Tamhane, K. Brix, G.M. Maelandsmo, K. Flatmark, High expression of the cysteine proteinase legumain in colorectal cancerimplications for therapeutic targeting. Eur J Cancer 51, 9-17 (2015)

27. M. Holland, F.V. Castro, S. Alexander, D. Smith, J. Liu, M. Walker, D. Bitton, K. Mulryan, G. Ashton, M. Blaylock, S. Bagley, Y. Connolly, J. Bridgeman, C. Miller, S. Krishnan, C. Dempsey, A. Masurekar, P. Stern, A. Whetton, V. Saha, RAC2, AEP, and ICAM1 expression are associated with CNS disease in a mouse model of pre-B childhood acute lymphoblastic leukemia. Blood 118, 638649 (2011)

28. L. Wang, S. Chen, M. Zhang, N. Li, Y. Chen, W. Su, Y. Liu, D. Lu, S. Li, Y. Yang, Z. Li, D. Stupack, P. Qu, H. Hu, R. Xiang, Legumain: A biomarker for diagnosis and prognosis of human ovarian cancer. J Cell Biochem 113, 2679-2686 (2012)

29. M. Colombo, G. Raposo, C. Thery, Biogenesis, secretion, and intercellular interactions of exosomes and other extracellular vesicles - Annual review of cell and developmental biology. Annu Rev Cell Dev Biol 30, 255-289 (2014)

30. P. Nilendu, S.C. Sarode, D. Jahagirdar, I. Tandon, S. Patil, G.S. Sarode, J.K. Pal, N.K. Sharma, Mutual concessions and compromises between stromal cells and cancer cells: Driving tumor development and drug resistance. Cell Oncol 41, 353-367 (2018)

31. L. Zhang, S. Zhang, J. Yao, F.J. Lowery, Q. Zhang, W.C. Huang, P. Li, M. Li, X. Wang, C. Zhang, H. Wang, K. Ellis, M. Cheerathodi, J.H. McCarty, D. Palmieri, J. Saunus, S. Lakhani, S. Huang, A.A. Sahin, K.D. Aldape, P.S. Steeg, D. Yu, Microenvironment-induced PTEN loss by exosomal microRNA primes brain metastasis outgrowth. Nature 527, 100-104 (2015)

32. N.P. Bretz, R. Johannes, R. Anne-Kathleen, R. Katharina, K. Sascha, R. Christian, M. Frederik, U. Ludmila, U. Viktor, E. Tatjana, S. Marei, A. Peter, Body fluid exosomes promote secretion of inflammatory cytokines in monocytic cells via Toll-like receptor signaling. J Biol Chem 288, 36691-36702 (2013)

33. V.O. Shender, M.S. Pavlyukov, R.H. Ziganshin, G.P. Arapidi, S.I. Kovalchuk, N.A. Anikanov, I.A. Altukhov, D.G. Alexeev, I.O. Butenko, A.L. Shavarda, E.B. Khomyakova, E. Evtushenko, L.A. Ashrafyan, I.B. Antonova, I.N. Kuznetcov, A.Y. Gorbachev, M.I. Shakhparonov, V.M. Govorun, Proteome-metabolome profiling of ovarian cancer ascites reveals novel components involved in intercellular communication. Mol Cell Proteomics 13, 3558-3571 (2014)

34. E. Stylianou, L.A. Jenner, M. Davies, G.A. Coles, J.D. Williams, Isolation, culture and characterization of human peritoneal mesothelial cells. Kidney Int 37, 1563-1570 (1990)

35. Y. Lin, K. Liao, Y. Miao, Z. Qian, Z. Fang, X. Yang, Q. Nie, G. Jiang, J. Liu, Y. Yu, J. Wan, X. Zhang, Y. Hu, J. Jiang, Y. Qiu, Role of asparagine endopeptidase in mediating wild-type p53 inactivation of glioblastoma. J Natl Cancer Inst 8, 155 (2019)

36. Y. Miao, G. Li, X. Zhang, H. Xu, S.N. AbrahamAbraham, A TRP channel senses lysosome neutralization by pathogens to trigger their expulsion. Cell 161, 1306-1319 (2015)

37. D. Cao, Z. Qi, Y. Pang, H. Li, H. Xie, J. Wu, Y. Huang, Y. Zhu, Y. Shen, Y. Zhu, B. Dai, X. Hu, D. Ye, Z. Wang, Retinoic acid-related orphan receptor $\mathrm{C}$ regulates proliferation, glycolysis, and chemoresistance via the PD-L1/ITGB6/STAT3 signaling axis in bladder cancer. Cancer Res 79, 2604-2618 (2019) 
38. Q. Jiang, Y. Pan, Y. Cheng, H. Li, D. Liu, H. Li, Lunasin suppresses the migration and invasion of breast cancer cells by inhibiting matrix metalloproteinase-2/-9 via the FAK/Akt/ERK and NF- $\mathrm{KB}$ signaling pathways. Oncol Rep 36, 253-262 (2016)

39. J.A.D.L. Mare, T. Jurgens, A.L. Edkins, Extracellular Hsp90 and $\mathrm{TGFI}^{2}$ regulate adhesion, migration and anchorage independent growth in a paired colon cancer cell line model. BMC Cancer 17, 202-211 (2017)

40. L.E. Reynolds, G. DAmico, T. Lechertier, A. Papachristodoulou, J.M. Munoz-Felix, A.A. De, M. Baker, B. Serrels, K.M. HodivalaDilke, Dual role of pericyte $\alpha 6 \beta 1$-integrin in tumour blood vessels. J Cell Sci 130, 1583-1595 (2017)

41. L.A. Caromile, K. Dortche, M.M. Rahman, C.L. Grant, C. Stoddard, F.A. Ferrer, L.H. Shapiro, PSMA redirects cell survival signaling from the MAPK to the PI3K-AKT pathways to promote the progression of prostate cancer. Sci Signal 10, 1-13 (2017)

42. S. Paget, The distribution of secondary growths in cancer of the breast. 1889. Cancer Metastasis Rev 8, 98-101 (1989)

43. A. Hoshino, B. Costa-Silva, T.-L. Shen, G. Rodrigues, A. Hashimoto, M.T. Mark, H. Molina, S. Kohsaka, A.D. Giannatale, S. Ceder, S. Singh, C. Williams, N. Soplop, K. Uryu, L. Pharmer, T. King, L. Bojmar, A.E. Davies, Y. Ararso, T. Zhang, H. Zhang, J. Hernandez, J.M. Weiss, V.D. Dumont-Cole, K. Kramer, L.H. Wexler, A. Narendran, G.K. Schwartz, J.H. Healey, P. Sandstrom, K.J. Labori, E.H. Kure, P.M. Grandgenett, M.A. Hollingsworth, M.D. Sousa, S. Kaur, M. Jain, K. Mallya, S.K. Batra, W.R. Jarnagin, M.S. Brady, O. Fodstad, V. Muller, K. Pantel, A.J. Minn, M.J. Bissell, B.A. Garcia, Y. Kang, V.K. Rajasekhar, C.M. Ghajar, I. Matei, H. Peinado, J. Bromberg, D. Lyden, Tumour exosome integrins determine organotropic metastasis. Nature 527, 329-335 (2015)

44. J. Chen, P.M. Dando, N.D. Rawlings, M.A. Brown, N.E. Young, R.A. Stevens, E. Hewitt, C. Watts, A.J. Barrett, Cloning, isolation, and characterization of mammalian legumain, an asparaginyl endopeptidase. J Biol Chem 272, 8090-8098 (1997)

45. L. Zhao, T. Hua, C. Crowley, H. Ru, X. Ni, N. Shaw, L. Jiao, W. Ding, L. Qu, L.-W. Hung, W. Huang, L. Liu, K. Ye, S. Ouyang, G. Cheng, Z.-J. Liu, Structural analysis of asparaginyl endopeptidase reveals the activation mechanism and a reversible intermediate maturation stage. Cell Res 24, 344-358 (2014)
46. S. Bauer, Toll-like receptor 9 processing: The key event in toll-like receptor 9 activation? Immunol Lett 149, 85-87 (2013)

47. Y. Lin, C. Wei, Y. Liu, Y. Qiu, C. Liu, F. Guo, Selective ablation of tumor-associated macrophages suppresses metastasis and angiogenesis. Cancer Sci 104, 1217-1225 (2013)

48. S. Lewen, H. Zhou, H.D. Hu, T. Cheng, D. Markowitz, R.A. Reisfeld, R. Xiang, Y. Luo, A legumain-based minigene vaccine targets the tumor stroma and suppresses breast cancer growth and angiogenesis. Cancer Immunol Immunother 57, 507-515 (2008)

49. R.V. Murthy, G. Arbman, J. Gao, G.D. Roodman, X.F. Sun, Legumain expression in relation to clinicopathologic and biological variables in colorectal cancer. Clin Cancer Res 11, 2293-2299 (2005)

50. C. Liu, C.H. Sun, K. Janda, T. Edgington, Overexpression of legumain in tumors is significant for invasion/metastasis and a candidate enzymatic target for prodrug therapy. Cancer Res 63, 29572964 (2003)

51. N. Kosaka, Y. Yoshioka, Y. Fujita, T. Ochiya, Versatile roles of extracellular vesicles in cancer. J Clin Invest 126, 1163-1172 (2016)

52. M.Y. Mo, P.R.M. Siljander, Z. Andreu, A.B. Zavec, F.E. Borràs, E.I. Buzas, K. Buzas, E. Casal, F. Cappello, J. Carvalho, E. Colas, A.C. da Silva, S. Fais, J.M. Falcon-Perez, I.M. Ghobrial, B. Giebel, M. Gimona, M. Graner, I. Gursel, M. Gursel, N.H.H. Heegaard, A. Hendrix, P. Kierulf, K. Kokubun, M. Kosanovic, V. Kralj-Iglic, E.M. Krämer-Albers, S. Laitinen, C. Lässer, T. Lener, E. Ligeti, A. Line, G. Lipps, A. Llorente, J. Lotvall, M. Mancek-Keber, A. Marcilla, M. Mittelbrunn, I. Nazarenko, E.N.M.N.-t. Hoen, T.A. Nyman, L. O'Driscoll, M. Olivan, C. Oliveira, E. Pallinger, H.A. del Portillo, J. Reventos, M. Rigau, E. Rohde, M. Sammar, F. Sanchez-Madrid, N. Santarem, K. Schallmoser, M.S. Ostenfeld, W. Stoorvogel, R. Stukelj, S.G. Van der Grein, M.H. Vasconcelos, M.H.M. Wauben, O.D. Wever, Biological properties of extracellular vesicles and their physiological functions. J Extracell Vesicles 4, $1-14(2015)$

Publisher's note Springer Nature remains neutral with regard to jurisdictional claims in published maps and institutional affiliations. 